\title{
National Influenza Annual Report, Canada, 2020-2021, in the global context
}

\author{
Andrea Nwosu ${ }^{1 \star}$, Liza Lee ${ }^{1}$, Kara Schmidt ${ }^{1}$, Steven Buckrell ${ }^{1}$, Claire Sevenhuysen ${ }^{1}$, Christina Bancej ${ }^{1}$
}

\begin{abstract}
During the 2020-2021 Canadian influenza season, no community circulation of influenza occurred. Only 69 positive detections of influenza were reported, and influenza percent positivity did not exceed $0.1 \%$. Influenza indicators were at historical lows compared with the previous six seasons, with no laboratory-confirmed influenza outbreaks or severe outcomes being reported by any of the provinces and territories. Globally, influenza circulation was at historically low levels in both the Northern and the Southern Hemispheres. The decreased influenza activity seen in Canada and globally is concurrent with the implementation of nonpharmaceutical public health measures to mitigate the spread of the coronavirus disease 2019 (COVID-19). Although it is difficult to predict when influenza will begin to re-circulate, given the increased COVID-19 vaccination and the relaxation of public health measures, an influenza resurgence can be expected and may be more severe or intense than recent seasons. Influenza vaccination, along with non-pharmaceutical public health measures, continues to remain the best method to prevent the spread and impact of influenza. Public health authorities need to remain vigilant, maintain surveillance and continue to plan for heightened seasonal influenza circulation.
\end{abstract}

This work is licensed under a Creative Commons Attribution 4.0 Internationa License.

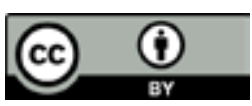

Affiliation

${ }^{1}$ Centre for Immunization and Respiratory Infectious Diseases, Public Health Agency of Canada, Ottawa, ON

\section{*Correspondence: \\ fluwatch-epigrippe@phac-aspc. gc.ca}

Suggested citation: Nwosu A, Lee L, Schmidt K, Buckrell S, Sevenhuysen C, Bancej C. National Influenza Annual Report, Canada, 2020-2021, in the global context. Can Commun Dis Rep 2021;47(10):405-13.

https://doi.org/10.14745/ccdr.v47i10a02

Keywords: influenza, influenza-like illness, surveillance, pandemic preparedness, outbreaks, COVID-19

\section{Introduction}

Public health measures implemented to reduce the spread of coronavirus disease 2019 (COVID-19) have impacted the transmission of influenza in every country around the world, including Canada (1-4). By the middle of Canada's 2020-2021 influenza season (week 50, ending December 12, 2020), seasonal influenza circulation in Canada was at unprecedented lows and had not approached the seasonal threshold (5). The following surveillance report provides a summary of Canada's 2020-2021 annual influenza season (August 23, 2020 to August 28, 2021) as well as the 2020-2021 Southern Hemisphere and 2020-2021 Northern Hemisphere influenza surveillance seasons.

FluWatch is a national influenza surveillance program that monitors the transmission of influenza and influenza-like illness (ILI) in Canada. Established in 1996, it is a pan-Canadian surveillance network of laboratories, hospitals, healthcare practitioners, individual Canadians and provincial and territorial ministries of health. The objectives of this program are as follows: 1) to identify signals for timely detection of, and coordinated assessment and response to, epidemics and other events of public health concern; 2) to contribute to the evidence base necessary for planning, development and implementation of health programs and healthy public policies for the control of influenza; and 3) to enable a robust surveillance infrastructure for the timely and relevant response and research necessary to mitigate the impacts of influenza (6).

\section{Method}

\section{Design}

The FluWatch program conducts prospective surveillance on influenza and ILI. Annually, influenza surveillance occurs from epidemiological week 35 to 34 of the following year. The FluWatch program is a composite surveillance system consisting of virologic surveillance, syndromic surveillance, influenza activity level surveillance, outbreak surveillance, severe outcome surveillance and vaccine monitoring. 

report are defined in Table 1. monitored through the FluWatch program and presented in this
Indicator definitions

Standardized definitions of the core indicators that are

Table 1: FluWatch core indicators used to summarize the 2020-2021 influenza season in Canada

\begin{tabular}{|c|c|c|c|}
\hline Indicator & Definition & Calculation & Data source \\
\hline $\begin{array}{l}\text { Influenza percent } \\
\text { positivity }\end{array}$ & $\begin{array}{l}\text { The weekly proportion of diagnostic tests } \\
\text { positive for influenza relative to all diagnostic } \\
\text { tests conducted. }\end{array}$ & $\begin{array}{l}\text { Numerator: The number of influenza } \\
\text { detections. } \\
\text { Denominator: The total number of influenza } \\
\text { diagnostic tests processed. }\end{array}$ & $\begin{array}{l}\text { Respiratory Virus } \\
\text { Detection Surveillance } \\
\text { System and FluNet }\end{array}$ \\
\hline $\begin{array}{l}\text { Influenza strain } \\
\text { characterization }\end{array}$ & $\begin{array}{l}\text { The number of influenza isolates } \\
\text { characterized by the National Microbiology } \\
\text { Laboratory compared to recent Canadian } \\
\text { and global isolates and World Health } \\
\text { Organization recommended vaccine strain } \\
\text { viruses. }\end{array}$ & $\begin{array}{l}\text { Counts and proportions antigenically } \\
\text { similar/dissimilar to the vaccine strains. }\end{array}$ & $\begin{array}{l}\text { National Microbiology } \\
\text { Laboratory }\end{array}$ \\
\hline $\begin{array}{l}\text { Proportion of visits for } \\
\text { ILI }\end{array}$ & $\begin{array}{l}\text { The weekly proportion of patient-visits to } \\
\text { sentinel practitioners due to ILI relative to all } \\
\text { patient-visits. }\end{array}$ & $\begin{array}{l}\text { Numerator: The number of patient visits for } \\
\text { ILI seen at sentinel sites. } \\
\text { Denominator: The total number of patients } \\
\text { seen at sentinel sites for any reason. }\end{array}$ & $\begin{array}{l}\text { Sentinel Practitioner ILI } \\
\text { Reporting system }\end{array}$ \\
\hline $\begin{array}{l}\text { Proportion of } \\
\text { FluWatcher participants } \\
\text { with ILI }\end{array}$ & $\begin{array}{l}\text { The weekly proportion of FluWatcher } \\
\text { participants self-reporting cough and fever, } \\
\text { relative to all FluWatcher participants. }\end{array}$ & $\begin{array}{l}\text { Numerator: The number of FluWatchers } \\
\text { participants reporting cough and fever. } \\
\text { Denominator: The total number of } \\
\text { participants reporting to FluWatchers. }\end{array}$ & FluWatchers \\
\hline Influenza outbreaks & $\begin{array}{l}\text { The number of influenza or ILI outbreaks by } \\
\text { setting and influenza type. }\end{array}$ & $\begin{array}{l}\text { Counts and proportions of outbreaks by } \\
\text { setting and influenza/ILI type. }\end{array}$ & $\begin{array}{l}\text { Provincial and territorial } \\
\text { public health authorities }\end{array}$ \\
\hline $\begin{array}{l}\text { Influenza-associated } \\
\text { hospitalizations }\end{array}$ & $\begin{array}{l}\text { The number and rate of hospitalizations that } \\
\text { are associated with influenza. }\end{array}$ & Counts and rates per 100,000 population. & $\begin{array}{l}\text { Provincial and territorial } \\
\text { public health authorities, } \\
\text { Immunization Monitoring } \\
\text { Program Active and } \\
\text { Canadian Immunization } \\
\text { Research Network }\end{array}$ \\
\hline $\begin{array}{l}\text { Vaccine effectiveness } \\
\text { against medically- } \\
\text { attended influenza }\end{array}$ & $\begin{array}{l}\text { The proportionate reduction in influenza } \\
\text { among those vaccinated, relative to those } \\
\text { unvaccinated among medically attended ILI. }\end{array}$ & $\begin{array}{l}\text { Vaccine effectiveness estimates are based } \\
\text { on the results of a modified case control } \\
\text { study (test negative design) and derived } \\
\text { using the following equation: } \\
V E=100 \% *\left(1-\frac{O_{\text {pos }}}{O_{\text {meg }}}\right) \\
\text { where } O_{\text {pos }} \text { is the odds of vaccination } \\
\text { among those testing positive for influenza } \\
\text { and } O_{\text {neg }} \text { is the odds of vaccination among } \\
\text { those testing negative. }\end{array}$ & $\begin{array}{l}\text { Canadian Sentinel } \\
\text { Practitioners Surveillance } \\
\text { Network }\end{array}$ \\
\hline $\begin{array}{l}\text { Vaccine effectiveness } \\
\text { against influenza } \\
\text { associated } \\
\text { hospitalization }\end{array}$ & $\begin{array}{l}\text { The proportionate reduction in influenza } \\
\text { among those vaccinated, relative to those } \\
\text { unvaccinated among adults hospitalized for } \\
\text { acute respiratory illness. }\end{array}$ & $\begin{array}{l}\text { Vaccine effectiveness estimates are based } \\
\text { on the results of a modified case control } \\
\text { study (test negative design) and derived } \\
\text { using the following equation: } \\
V E=100 \% *\left(1-\frac{O_{\text {pos }}}{O_{\text {neg }}}\right) \\
\text { where } O_{\text {pos }} \text { is the odds of vaccination } \\
\text { among those testing positive for influenza } \\
\text { and } O_{\text {neg }} \text { is the odds of vaccination among } \\
\text { those testing negative. }\end{array}$ & $\begin{array}{l}\text { Canadian Immunization } \\
\text { Research Network }\end{array}$ \\
\hline $\begin{array}{l}\text { Influenza vaccination } \\
\text { coverage }\end{array}$ & $\begin{array}{l}\text { The percentage of Canadians aged six } \\
\text { months and older who received one dose of } \\
\text { seasonal influenza vaccine during the current } \\
\text { influenza season. }\end{array}$ & $\begin{array}{l}\text { Numerator: number of people who } \\
\text { received the influenza vaccine for that } \\
\text { season. } \\
\text { Denominator: the number of people } \\
\text { eligible for the vaccine that season. }\end{array}$ & $\begin{array}{l}\text { Public Health Agency } \\
\text { of Canada's National } \\
\text { Influenza Immunization } \\
\text { Coverage Survey }\end{array}$ \\
\hline
\end{tabular}




\section{Data sources}

Canadian virologic data: Aggregate and case-level data on influenza detections are reported to FluWatch through the Respiratory Virus Detection Surveillance System (7). The Respiratory Virus Detection Surveillance System is a sentinel laboratory-based system that monitors the temporal circulation of respiratory viruses in Canada at a national and regional level. This surveillance system consists of 34 laboratories reporting on the number of tests conducted and number of positive specimens for influenza and other respiratory viruses. Specimens from every province and territory are represented in the virologic data. Provincial laboratories provide individual case-level data.

Genetic and antigenic characterization data and antiviral susceptibility data: A proportion of laboratory-confirmed influenza detections undergo genetic and antigenic characterization and antiviral susceptibility testing. Results are provided by the Public Health Agency of Canada's National Microbiology Laboratory.

Global virologic data: FluNet is a global web-based tool for influenza virological surveillance (8). Virologic data from national influenza centres and laboratories in 75 countries are reported through this platform. Aggregate data on influenza testing and detections from countries/continents in the Northern (United States, Europe) and Southern Hemisphere (Australia, Chile, South Africa) were extracted from the World Health Organization's FluNet platform on September 11, 2021. Updated numbers of detections from Chile were unavailable in the September 11, 2021, extract from the FluNet database; therefore, a previous data extraction from July 27, 2021, was used.

Activity level and outbreak data: All provincial and territorial public health departments provide a categorical assessment (no activity, sporadic, localized or widespread) of the intensity and geographic spread of influenza (activity level) as well as the number of influenza and ILI outbreaks by setting and type and subtype for surveillance regions within their jurisdictions.

Syndromic data: Syndromic data are reported from two systems: the Sentinel Practitioner ILI Reporting system; and FluWatchers. The Sentinel Practitioner ILI Reporting system consists of healthcare practitioners across Canada who report the number of patients seen with ILI and the total number of patients seen by age group. FluWatchers consists of volunteers across Canada who report whether they had any influenza-like symptoms each week using an online questionnaire.

Severe outcome surveillance data: Data on influenza-associated severe outcomes (i.e. hospitalization, intensive care unit [ICU] admissions and deaths) are reported through three sources: 1) Provincial and territorial ministries of health-severe outcomes surveillance; 2) Canadian Immunization Monitoring Program
ACTive; and 3) Canadian Immunization Research Network's Serious Outcomes Surveillance Network.

Provincial/territorial severe outcome surveillance: Nine provincial and territorial ministries of health across Canada (Alberta, Manitoba, Saskatchewan, Nova Scotia, New Brunswick, Newfoundland and Labrador, Prince Edward Island, Yukon and Northwest Territories) participate and report case-level information (age, associated influenza type/subtype) for influenza-associated hospitalizations, ICU admissions and deaths.

Paediatric (16 years of age and younger) influenza-associated severe outcomes data: The Canadian Immunization Monitoring Program ACTive is a sentinel paediatric hospital network that consists of 12 paediatric hospitals across eight provinces in Canada. Detailed case-level information such as age, influenza type/subtype, gender, underlying medical conditions, vaccination status and treatment for influenza-associated hospitalizations, ICU admissions and in-patient deaths are reported on a weekly basis.

Adult (16 years of age and older) influenza-associated severe outcome data: The Canadian Immunization Research Network is a sentinel adult hospital network that consists of ten hospitals across four provinces. This network provides detailed caselevel information for influenza-associated hospitalizations, ICU admission and in-patient deaths.

Vaccine monitoring data: Data on influenza vaccine coverage are provided by the Public Health Agency of Canada's National Influenza Immunization Coverage Survey. Vaccine effectiveness data are provided through two networks, the Canadian Sentinel Practitioners Surveillance Network and Canadian Immunization Research Network's Severe Outcome Surveillance. The Canadian Sentinel Practitioners Surveillance Network provides estimates of how well the influenza vaccine prevents primary care visits for influenza. The Canadian Immunization Research Network's Severe Outcome Surveillance estimates how effective the seasonal influenza vaccine is in preventing hospitalization in adults. During a typical influenza surveillance season both interim and final estimates are provided.

\section{Statistical analysis}

Temporal and geographic trends in the core surveillance indicators (Table 1) were monitored throughout the season. Case counts and proportions are presented and compared, where available, with historical data from the 2014-2015 to 2019-2020 season. All analyses were performed using SAS PC 9.4 for Windows. 


\section{Results}

\section{Laboratory-confirmed influenza detections}

There was no community circulation of influenza in Canada during the 2020-2021 season. A total of 69 laboratory-confirmed influenza virus detections were reported during the 2020-2021 influenza season, all representing sporadic activity; 31 of these detections were associated with receipt of live attenuated influenza vaccine $(9,10)$. Influenza $A$ accounted for $67 \%(n=46)$ of reported detections. Only 20 influenza $A$ viruses were subtyped; thus, subtype characteristics of the sporadic detections could not be ascertained.
Despite few reported detections, high levels of influenza testing that were above seasonal averages were maintained throughout the 2020-2021 influenza season, with a total of 632,580 tests reported. Historically, during the non-pandemic surveillance seasons 2014-2015 to 2018-2019, the total number of tests conducted ranged from 237,777 to 391,862 . The percentage of laboratory tests positive for influenza remained at exceptionally low levels throughout the 2020-2021 influenza season. The reported percent positivity ranged from $0.0 \%$ to $0.1 \%$ this season compared to a historical average range of $0.8 \%$ to $25.1 \%$ while testing through the season was roughly twice the historical average (Figure 1).

Figure 1: Number of influenza tests and percentage of tests positive, in Canada, United States and Europe, by surveillance week

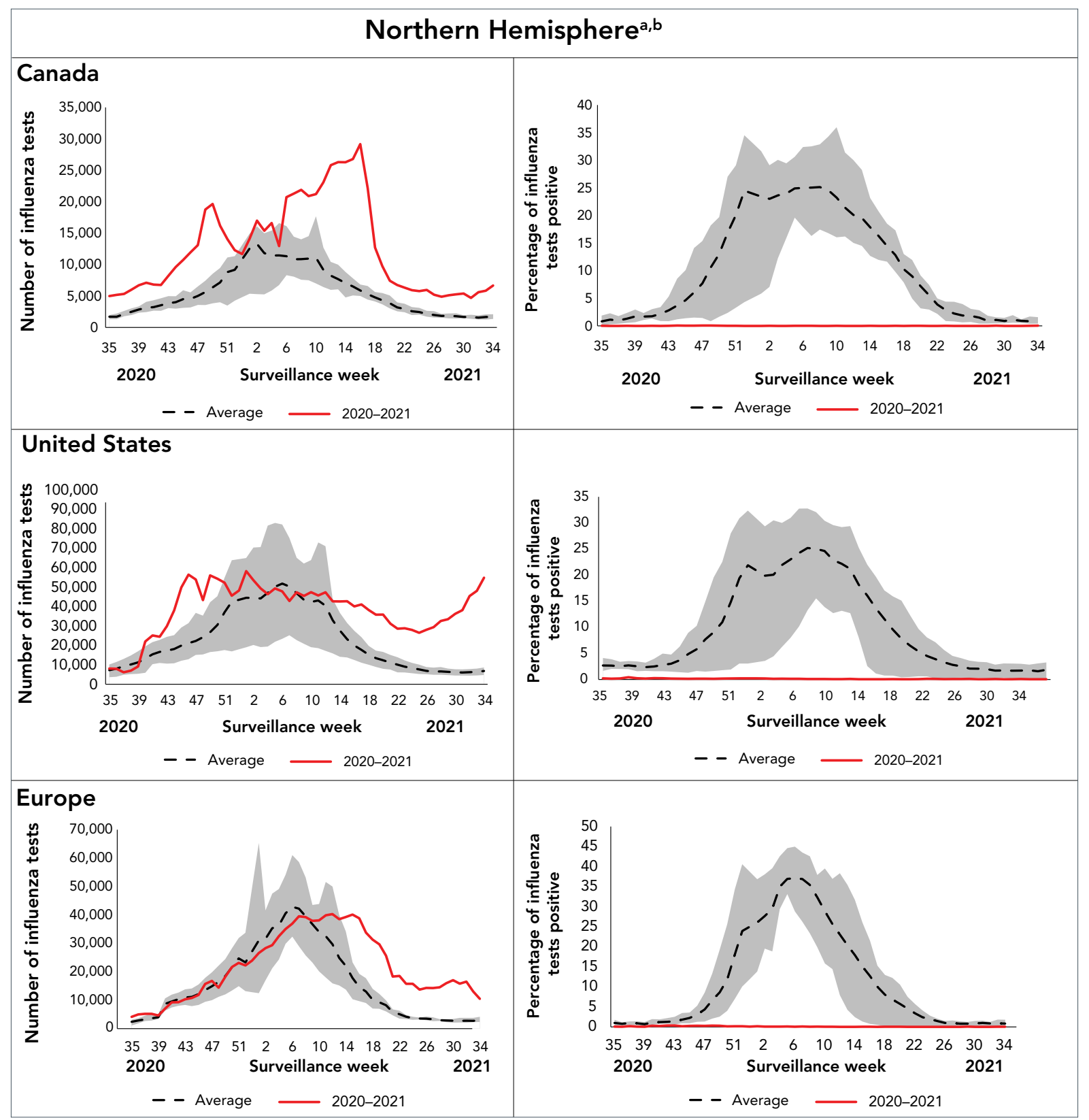


Figure 1: Number of influenza tests and percentage of tests positive, in Canada, United States and Europe, by surveillance week (continued)

\section{Southern Hemisphere ${ }^{a, c}$}
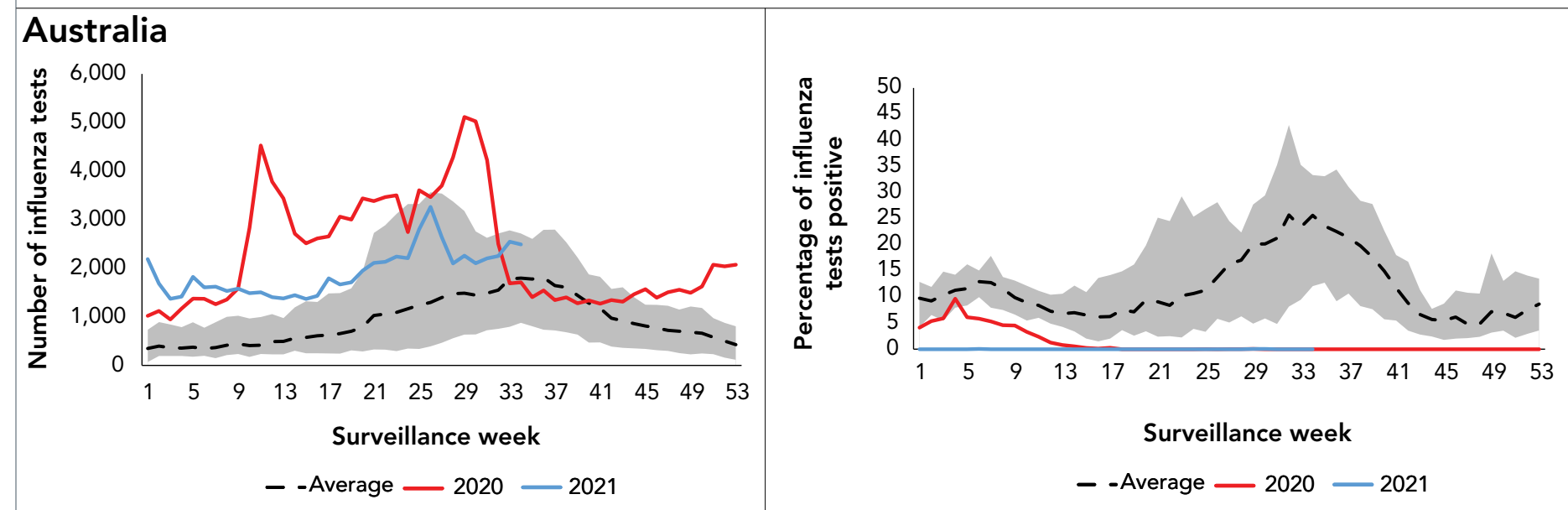

\section{Chile}
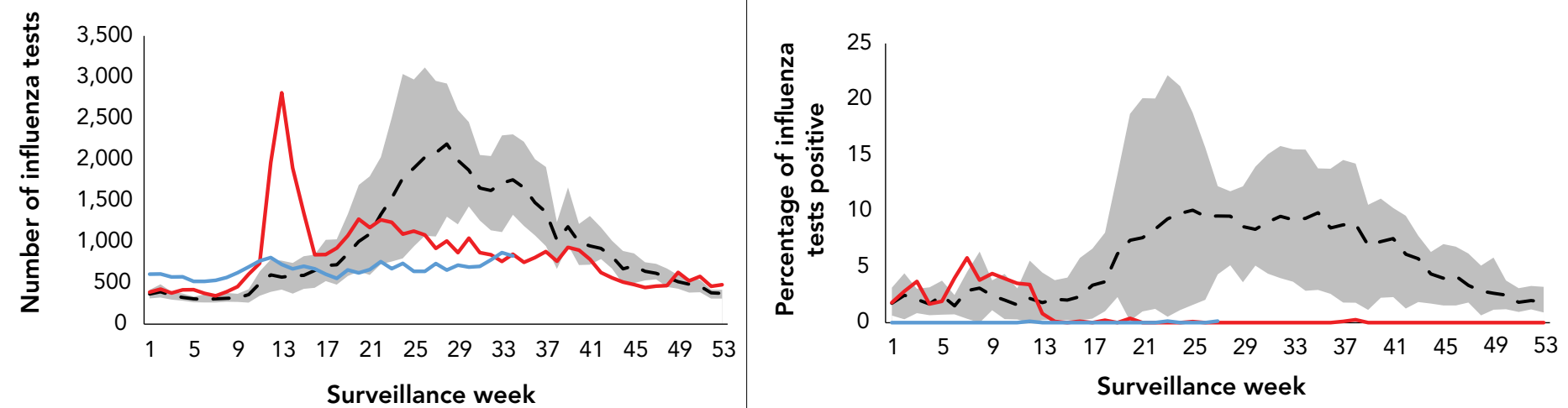

- -Average — $2020-2021$

\section{South Africa}

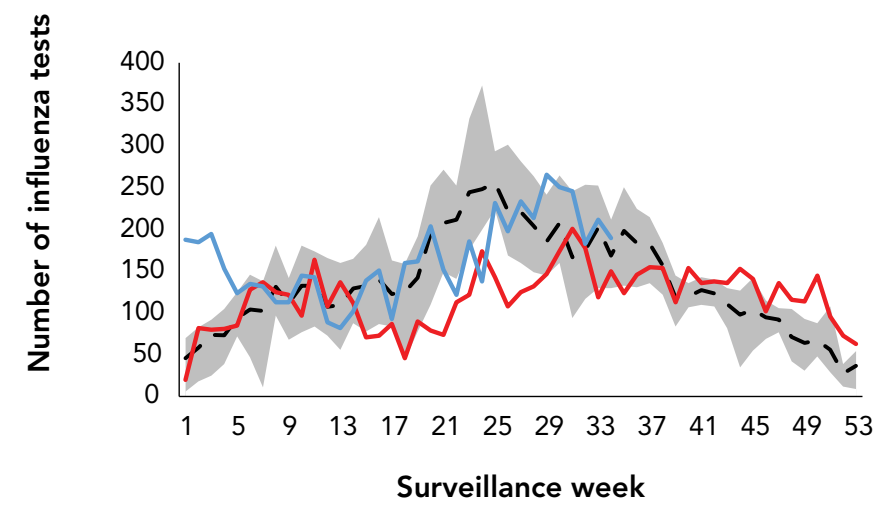

- - Average - $2020-2021$

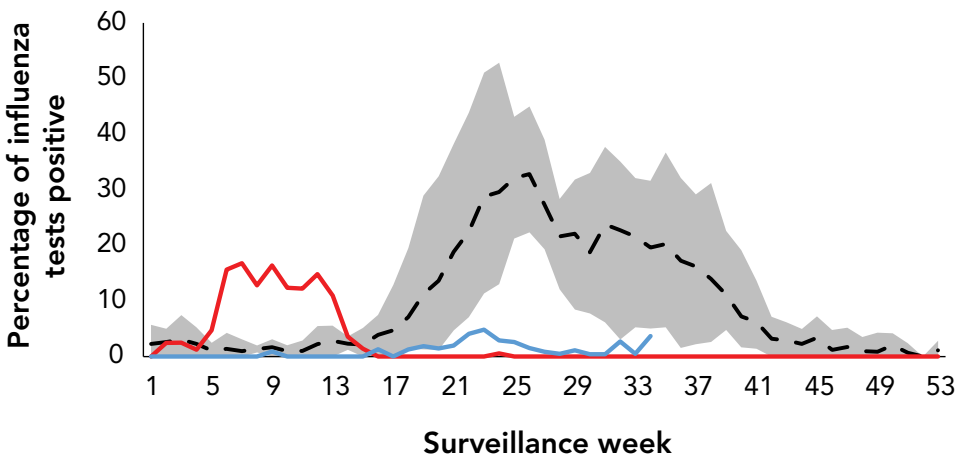

- -Average $-2020-2021$

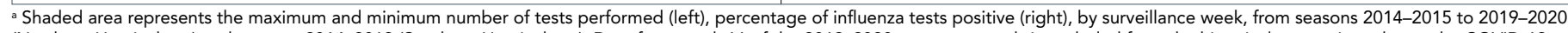
(Northern Hemisphere) and seasons 2014-2019 (Southern Hemisphere). Data from week 11 of the 2019-2020 season onwards is excluded from the historical comparison due to the COVID-19 pandemic

b 2020-2021 Northern Hemisphere influenza season in Canada, United States and Europe compared to historical average (seasons 2014-2015 to 2019-2020) c 2020-2021 Southern Hemisphere influenza seasons in Australia, Chile and South Africa compared to historical average (seasons 2014 to 2019) 
The influenza $B$ virus that was characterized was antigenically related to B/Washington/02/2019 (Victoria). The four zoonotic infections were swine influenza variants $\mathrm{H} 1 \mathrm{~N} 2 \mathrm{v}(\mathrm{n}=2), \mathrm{H} 3 \mathrm{~N} 2 \mathrm{v}$ $(n=1)$ and H1N1v $(n=1)(11-14)$.

\section{Syndromic}

Both syndromic surveillance programs within FluWatch showed lower than usual activity, which is not unexpected given the lack of community circulation of influenza. Throughout the season, there were small fluctuations in ILI activity (Figure 2). These fluctuations in activity were likely signals of other respiratory virus activity such as enterovirus/rhinovirus, respiratory syncytial virus, adenovirus and severe acute respiratory syndrome coronavirus 2 (SARS-CoV-2).

\section{Healthcare practitioners sentinel syndromic surveillance}

The healthcare practitioners sentinel ILI surveillance system reported below average percentages of visits due to ILI compared with previous seasons. Weekly percentages of visits due to ILI have ranged from $0.06 \%-0.49 \%$ (compared to the six-year average range of $0.41 \%-3.32 \%$ ). This is not unexpected given the changes in healthcare seeking behaviour, the additional healthcare options for individuals with ILI symptoms, a reduction in the number of sentinels reporting and the average number of weekly patients seen. In the previous season, a weekly average of 94 sentinels reported and an average of 8,775 patients were seen compared with the current season's weekly average of 62 sentinels reporting and an average of 5,503 patients seen.

For the majority of the season, the highest weekly percentage of visits for ILI was reported among those younger than 20 years of age. The lowest percentage of visits for ILI was reported

Figure 2: Percentage of visits for influenza-like illnesses reported by healthcare practitioners sentinel syndromic surveillance and FluWatchers participants reporting fever and cough ${ }^{a}$, by surveillance week, Canada, season 2020-2021, compared to historical average

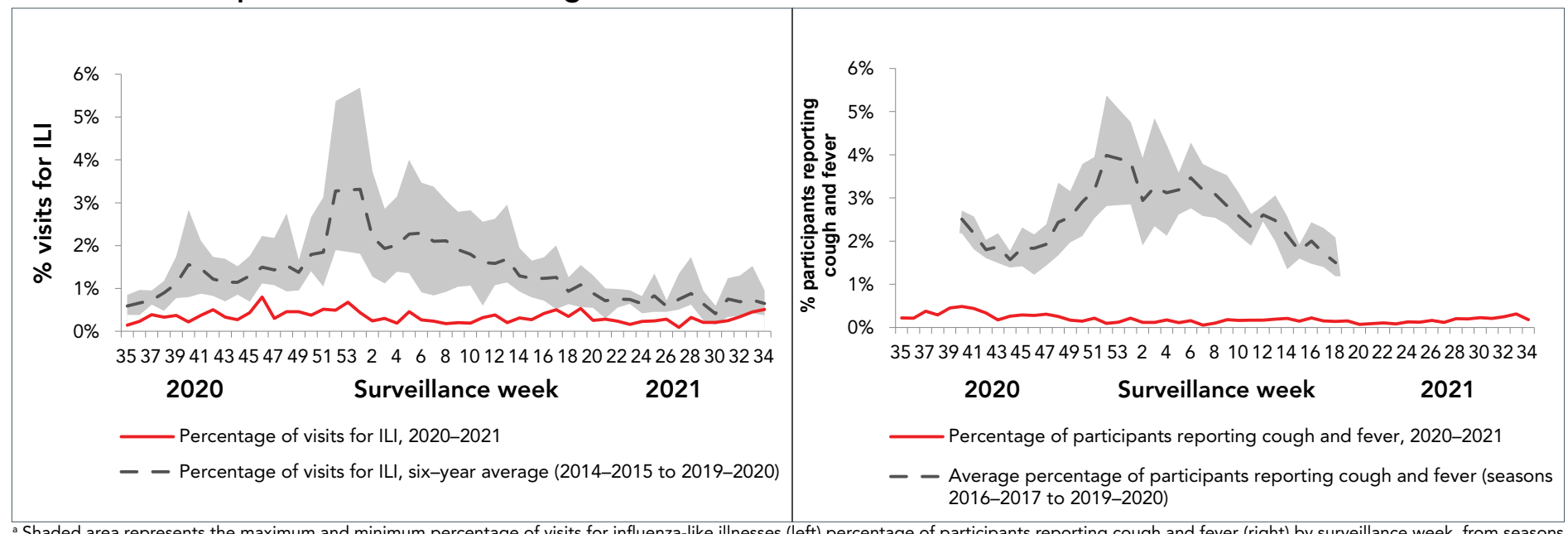


among adults 65 years of age and older. This trend was similar to that seen in previous seasons, despite the reduced number of patients and the lower percentages of visits due to ILI.

\section{FluWatchers}

The FluWatchers program reported below average percentages of participants reporting fever and cough compared with previous seasons. Weekly percentage of reports of fever and cough have ranged from $0.1 \%-0.5 \%$, compared to the four-year average range of $1.5 \%-4.0 \%$. On average 12,048 participants reported weekly (range 9,290-12,831), which is approximately 3.5 times higher than the previous season. FluWatchers reporting is not impacted by changes in health services or health seeking behaviour; however, these low reports of cough and fever may be a direct effect of individual and/or public health measures enacted to reduce the spread of COVID-19.

Similar to the healthcare practitioners sentinel syndromic surveillance, for the majority of the season, the highest weekly percentages of participants reporting cough and fever were among those younger than 20 years of age. The lowest weekly percentages of participants reporting cough and fever were among adults 65 years of age and older. This trend is similar to that seen in previous seasons.

\section{Outbreaks}

All outbreaks reported during the season $(n=138)$ were ILI outbreaks in schools and/or daycares. The number of ILI outbreaks in schools and/or daycares was higher compared with the previous two seasons. This is not unexpected given changes to outbreak surveillance, specifically the increased vigilance in schools to monitor and report absenteeism due to ILI, and the increased restrictions on attendance for children with symptoms of viral respiratory illness.

No laboratory-confirmed influenza outbreaks were reported this season.

\section{Severe outcomes}

No influenza-associated hospitalizations were reported by participating provinces and territories (Alberta, Manitoba, New Brunswick, Newfoundland and Labrador, Northwest Territories, Nova Scotia, Prince Edward Island and Yukon).

No influenza-associated hospitalizations were reported by the adult sentinel influenza hospitalization network (Canadian Immunization Research Network) and fewer than five influenza-associated hospitalizations were reported by the paediatric sentinel influenza hospitalization network (Canadian Immunization Monitoring Program ACTive).

\section{Vaccine monitoring}

The World Health Organization recommended that the 2020-21 Northern Hemisphere egg-based influenza vaccine contain the following strains (15):

- A/Guangdong-Maonan/SWL1536/2019 (H1N1)pdm09-like virus

- $\mathrm{A} /$ Hong Kong/2671/2019 (H3N2)-like virus

- $\mathrm{B} /$ Washington/02/2019 (B/Victoria lineage)-like virus

- $\mathrm{B} /$ Phuket/3073/2013 (B/Yamagata lineage)-like virus (quadrivalent vaccine only)

\section{Vaccine coverage}

Vaccine coverage for the 2020-2021 influenza season was similar to the previous season. Thirty-two percent of adults 18 to 64 years of age received their influenza vaccine (10). Vaccine coverage was higher among seniors aged 65 years and older (70\%) and adults with chronic medical conditions (40\%). Overall vaccine coverage was higher amongst females compared to males.

\section{Vaccine effectiveness}

Due to an absence of seasonal influenza circulation no estimates of influenza vaccine effectiveness could be produced for Canada nor any Northern or Southern Hemisphere country since the 2019-2020 Northern Hemisphere influenza season.

\section{Discussion}

The 2020-2021 Canadian influenza season was characterized by sporadic influenza detection and the absence of sustained circulation of the virus within the community. In Canada, non-pharmaceutical public health measures (i.e. school closures, travel restrictions, mandatory masking and increased handwashing) were implemented in March 2020 and maintained throughout the 2020-2021 flu season to reduce the transmission of COVID-19. Epidemiological analysis of laboratory influenza data have shown that these measures were effective in reducing the incidence and impact of influenza in Canada $(3,4)$. Despite elevated respiratory virus testing this season, only 69 influenza viruses were detected, and influenza percent positivity did not exceed $0.1 \%$. Historically, on average, 52,169 influenza viruses were detected within a season with the percent positivity ranging from $0.8 \%-25.1 \%$. Decreased influenza circulation was also observed in other countries around the world. Laboratory data submitted to the World Health Organization's FluNet program showed that during the 2020 Southern Hemisphere, 20202021 Northern Hemisphere and 2021 Southern Hemisphere influenza seasons, Australia, Chile, South Africa, the United States and countries in Europe also experienced decreased influenza activity for the majority of their surveillance season. As of week 34 of 2021 (week 27 for Chile), laboratory data from the 2021 Southern Hemisphere influenza season showed 
enhanced surveillance and knowledge exchange on influenza vaccine effectiveness to FluWatch: Canada's Immunization Monitoring Program ACTive, Canadian Immunization Research Network Serious Outcomes Surveillance Network, and the Canadian Influenza Sentinel Practitioner Surveillance Network. Finally, we wish to acknowledge the National Microbiology Laboratory's Influenza and Respiratory Virus section for the strain characterization and antiviral resistance testing data and the Centre for Immunization and Respiratory Infectious Diseases' Vaccination Coverage Section for their analysis of the annual national Seasonal Influenza Vaccination Coverage Surveys.

\section{Funding}

FluWatch surveillance is funded by the Public Health Agency of Canada.

\section{References}

1. Olsen SJ, Azziz-Baumgartner E, Budd AP, Brammer L, Sullivan S, Pineda RF, Cohen C, Fry AM. Decreased Influenza Activity During the COVID-19 Pandemic - United States, Australia, Chile, and South Africa, 2020. MMWR Morb Mort Wkly Rep. 2020;69:1305-9. https://www.cdc.gov/mmwr/ volumes/69/wr/mm6937a6.htm

2. World Health Organization. Global Influenza Programme. Influenza Update No 398. Geneva, Switzerland: WHO; 2021 (accessed 2021-07-28). https://cdn.who. int/media/docs/default-source/influenza/influenzaupdates/2021/2021_07_19_surveillance_update_398.pdf?sfv rsn=cc48538f_5\&download=true

3. Groves HE, Piché-Renaud PP, Peci A, Farrar DS, Buckrell S, Bancej C, Sevenhuysen C, Campigotto A, Gubbay JB, Morris SK. The impact of the COVID-19 pandemic on influenza, respiratory syncytial virus, and other seasonal respiratory virus circulation in Canada: A population-based study. Lancet Reg Health Am 2021;1:100015. DOI PubMed

The FluWatch team in the Centre for Immunization and Respiratory Infectious Diseases developed the first draft collaboratively; all authors contributed to the conceptualization, writing and revision of the manuscript.

\section{Competing interests}

None.

\section{Acknowledgements}

Many thanks to all those across Canada who contribute to influenza surveillance. The FluWatch program consists of a volunteer network of labs, hospitals, doctor's offices, provincial and territorial ministries of health and individual Canadians who contribute as FluWatchers. We also acknowledge the following surveillance and research networks who contribute
4. Lagacé-Wiens P, Sevenhuysen C, Lee L, Nwosu A, Smith T. Impact of nonpharmaceutical interventions on laboratory detections of influenza A and B in Canada. Can Commun Dis Rep 2021;47(3):142-8. DOI PubMed

5. Lee L, Butt K, Buckrell S, Nwosu A, Sevenhuysen C, Bancej C. National influenza mid-season report, 2020-2021. Can Commun Dis Rep 2021;47(1):1-4. DOI PubMed

6. Public Health Agency of Canada. Flu (influenza): FluWatch surveillance. Overview of Influenza monitoring in Canada. Ottawa (ON): PHAC; 2021 (accessed 2021-07-28). https://www.canada.ca/en/public-health/services/diseases/ flu-influenza/influenza-surveillance/about-fluwatch.html

7. Public Health Agency of Canada. Flu (influenza): FluWatch surveillance. Respiratory Virus Detections in Canada. Ottawa (ON): PHAC; 2021 (accessed 2021-07-28). https://www. canada.ca/en/public-health/services/surveillance/respiratoryvirus-detections-canada.html 
8. World Health Organization. Global Influenza Programme. FluNet. Geneva, Switzerland: WHO; 2021 (accessed 2021-07-27). https://www.who.int/tools/flunet

9. Public Health Agency of Canada. National Advisory Committee on Immunization (NACl). Canadian Immunization Guide Chapter on Influenza and Statement on Seasonal Influenza Vaccine for 2020-2021. Ottawa (ON): PHAC; 2020 (accessed 2021-07-28). https://www.canada.ca/en/ public-health/services/publications/vaccines-immunization/ canadian-immunization-guide-statement-seasonal-influenzavaccine-2020-2021.html\#IV2

10. Public Health Agency of Canada. Flu (influenza): FluWatch surveillance. FluWatch report: July 25, 2021 to August 28, 2021 (weeks 30-34). Ottawa (ON): PHAC; 2021 (accessed 2021-09-03). https://www.canada.ca/en/ public-health/services/publications/diseases-conditions/ fluwatch/2020-2021/weeks-21-24-may-23-june-19-2021.html

11. Public Health Agency of Canada. Human Emerging Respiratory Pathogens Bulletin: Issue 47, November 2020. Ottawa (ON): PHAC; 2020 (accessed 2021-07-28). https://www.canada.ca/en/public-health/services/ surveillance/human-emerging-respiratory-pathogensbulletin/2020/november.html

12. Public Health Agency of Canada. Human Emerging Respiratory Pathogens Bulletin: Issue 52, April 2021. Ottawa (ON): PHAC; 2020 (accessed 2021-07-28). https://www. canada.ca/en/public-health/services/surveillance/humanemerging-respiratory-pathogens-bulletin/2021/april.html
13. Public Health Agency of Canada. Human Emerging Respiratory Pathogens Bulletin: Issue 54, June 2021. Ottawa (ON): PHAC; 2020 (accessed 2021-07-28). https://www. canada.ca/en/public-health/services/surveillance/humanemerging-respiratory-pathogens-bulletin/2021/june.html

14. World Health Organization. Global Influenza Programme. Recommended composition of influenza virus vaccines for use in the 2020-2021 northern hemisphere influenza season. Geneva, Switzerland: WHO; 2020 (accessed 2021-07-28). https://www.who.int/publications/m/item/recommendedcomposition-of-influenza-virus-vaccines-for-use-in-the-20212022-northern-hemisphere-influenza-season

15. The Academy of Medical Sciences. COVID-19: Preparing for the future. London, UK: AMS; 2021(accessed 2021-07-30). https://acmedsci.ac.uk/file-download/4747802

16. Baker RE, Park SW, Yang W, Vecchi GA, Metcalf CJ, Grenfell BT. The impact of COVID-19 nonpharmaceutical interventions on the future dynamics of endemic infections. Proc Natl Acad Sci USA 2020;117(48):30547-53. DOI PubMed

17. Centers for Disease Control and Prevention. Selecting Viruses for the Seasonal Influenza Vaccine. Atlanta (GA): CDC; (updated 2021-08-31; accessed 2021-08-30). https://www.cdc.gov/flu/prevent/vaccine-selection.htm 